\title{
Commuter exposure to fine and ultrafine particulate matter in Vienna
}

\author{
Georg Strasser · Stefan Hiebaum - Manfred Neuberger
}

Received: 18 July 2017 / Accepted: 8 September 2017 / Published online: 9 October 2017

(C) The Author(s) 2017. This article is an open access publication.

Summary Mass concentrations $\mathrm{PM}_{10}, \mathrm{PM}_{2.5}, \mathrm{PM}_{1}$, particle number concentrations of ultrafine particles and lung deposited surface area were measured during commutes with a subway, tram, bus, car and bicycle in Vienna for the first time. Obtained data were examined for significant differences in personal exposure when using various transport modalities along similar routes. Mean $\mathrm{PM}_{2.5}$ and $\mathrm{PM}_{1}$ mass concentrations were significantly higher in the subway when compared to buses. Mean $\mathrm{PM}_{10}, \mathrm{PM}_{2.5}$ and $\mathrm{PM}_{1}$ mass concentrations were significantly higher in the subway when compared to cars using low ventilation settings. Particle number concentrations of ultrafine particles were significantly higher in trams when compared to the subway and lung deposited surface area was significantly greater on bicycles when compared to the subway. After adjusting for different vehicle speeds, exposure to $\mathrm{PM}_{10}, \mathrm{PM}_{2.5}$ and $\mathrm{PM}_{1}$ along the same route length was significantly higher in the subway when compared to cars while exposure to ultrafine particles and partly also lung deposited surface area was significantly higher in bus, tram and on bicycle when compared to the subway. Car and bus passengers could be better isolated from ambient fine particulate matter than passengers in the subway, where a lot of ventilation occurs through open windows and larger doors. Tram passengers and cyclists might be exposed to increased amounts of ultrafine particles and larger lung deposited surface area due to a closer proximity to road traffic. Comparing cumulative exposure along the same route length leads to different results and favors faster traffic modes, such as the subway.

G. Strasser $\cdot$ S. Hiebaum $\cdot$ M. Neuberger $(\bowtie)$

Center for Public Health, Medical University of Vienna,

Kinderspitalgasse 15, 1090 Vienna, Austria

manfred.neuberger@meduniwien.ac.at
Keywords Air pollution - Fine particulate matter · Ultrafine particles $\cdot$ Lung deposited surface area $\cdot$ Commuting

\section{Introduction}

Evidence suggests that short and long-term exposure to fine particulate matter (FPM) is associated with increased long-term [1, 2] and short-term [3, 4] mortality. Associations with ultrafine particles (UFP) are weaker, possibly due to lack of comparable data and high variability of particle number concentration (PNC) in space and time [5] as well as the small number of studies available on lung deposited surface area (LDSA), a proxy for surfaces of UFP which come into contact with the cells in the respiratory tract.

In Vienna, increased levels of $\mathrm{PM}_{10}$ (particulate matter $\leq 10 \mu \mathrm{m}$ ) and $\mathrm{PM}_{2.5}$ have been shown to predict all-cause mortality [6] and $\mathrm{PM}_{2.5}$ has been linked to hospital admissions due to respiratory symptoms [7]. Motor traffic is one of the main contributors to atmospheric FPM in European cities [8]. Traffic-generated particles could have a stronger impact on mortality than particles from coal combustion or crustal particles [9]. Commuting via public or private transport tends to occur near urban traffic which leads to a considerably higher exposure to particulate air pollution. Numerous studies have tried to assess if and how choice of transport mode can impact personal exposure to FPM and UFP and have partly shown conflicting results. Exposure differences often vary when comparing mass/number concentrations of fine and ultrafine particles.

A recent study in Milan comparing walking, cycling, commuting by car and by subway found the highest mass concentration (MC) levels of fine particles in the subway followed by bike, walking and car whereas the PNC of UFP was highest while cycling, followed by 
Fig. 1 Map of the chosen traffic routes

\section{Map of the chosen traffic routes}

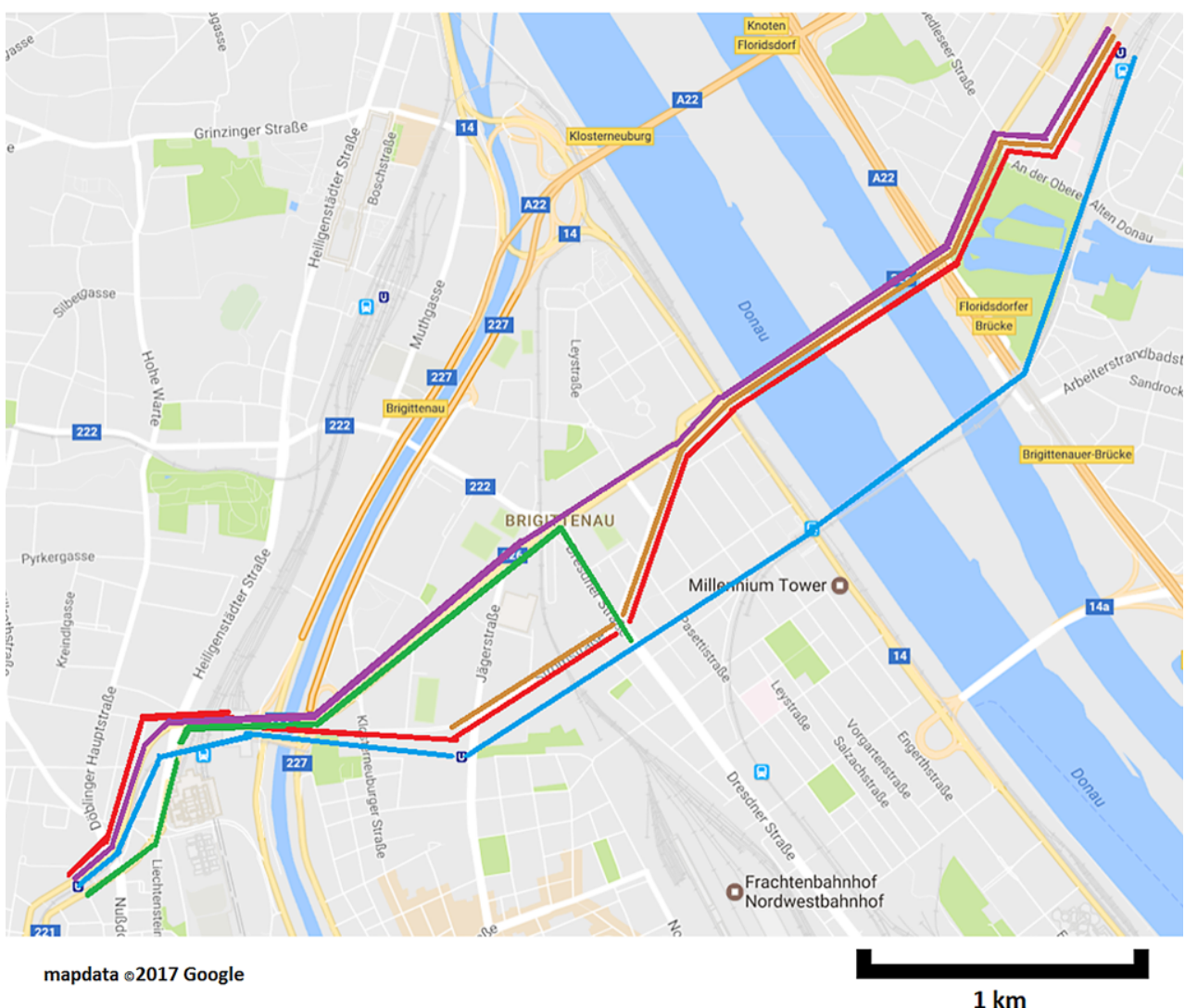

Subway Line U6 Floridsdorf - Nussdorferstraße

Bus Line 37a Nussdorferstraße - Dresdner Straße

Tram Line 31 Jägerstraße - Floridsdorf

Car Floridsdorf - Nussdorferstraße

Bike Floridsdorf - Nussdorferstraße walking, taking the subway and the car [10]. In Beijing $\mathrm{PM}_{2.5}$ levels were found to be highest in the subway, followed by walking, surface railway and bus, whereas PNC levels of ultrafine particles were highest in airconditioned bus, followed by surface railway, subway, walking and non-air-conditioned bus [11]. Results obtained in a study comparing bus, bicycle, car and subway in Santiago de Chile showed highest MC levels of $\mathrm{PM}_{2.5}$ in bus followed by subway, bicycle and car and PNC levels of UFP highest in bus, followed by bicycle, car and subway [12].

A study done in Barcelona comparing bus, tram subway and walking found higher $\mathrm{PM}_{2.5} \mathrm{MC}$ levels in subway and bus, compared to tram and highest PNC levels of ultrafine particles in the bus, followed by tram and subway [13]. In Hong Kong, $\mathrm{PM}_{10}$ exposure was shown to be highest in non-air-conditioned roadway transport, followed by marine transport, airconditioned roadway transport and railway transport [14]. Results of a study done in Arnhem, The Netherlands, showed higher $\mathrm{PM}_{10}$ levels in bus, followed by car and bicycle and higher $\mathrm{PM}_{2.5}$ levels in cars than in buses and on bicycles [15]. Drawing conclusions for other cities out of the growing pool of personal expo- sure studies is difficult due to differences in local city characteristics, such as weather, local emissions and properties of public and personal transport vehicles.

We conducted the first field study in Vienna, the capital of Austria, which has 2.6 million inhabitants in its metropolitan area, to explore for differences in personal exposure to $\mathrm{PM}_{10}, \mathrm{PM}_{2.5}, \mathrm{PM}_{1}$ and UFP/LDSA in subway, bus, tram, car and on the bicycle.

\section{Material and methods}

\section{Data collection}

We obtained mass concentrations of $\mathrm{PM}_{10}, \mathrm{PM}_{2.5}, \mathrm{PM}_{1}$ as well as particle number concentrations of ultrafine particles and LDSA using portable particle counters during commutes along typical commuter routes shown in Fig. 1 on 7 days between October 2015 and June 2016. The chosen area is typically utilized by commuters going to work in the inner city from the northeast urban and suburban parts of Vienna. The existence of busy streets and so many highly frequented public transport lines within a relatively 


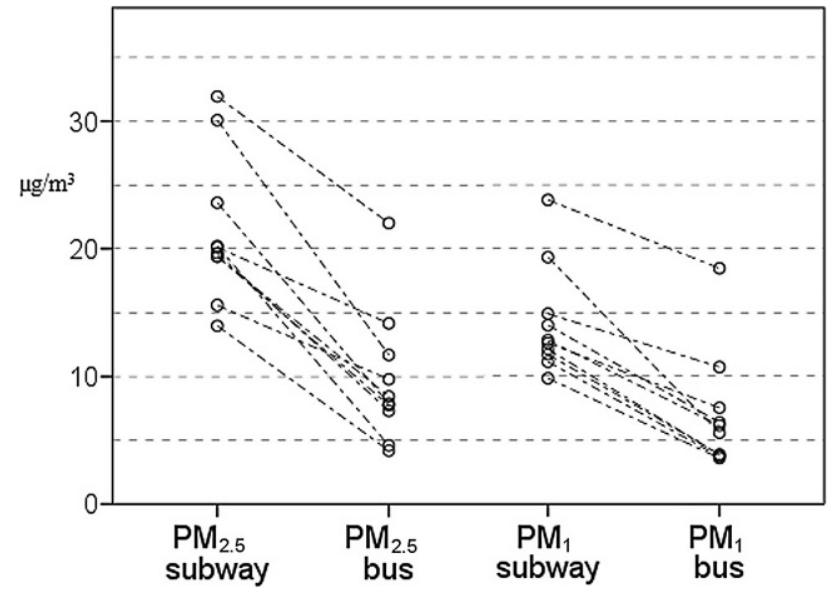

Fig. $2 \mathrm{PM}_{2.5}$ and $\mathrm{PM}_{1}$ data for subway and bus measurements

close distance is unique in this part of Vienna and invites comparisons between traffic modes.

Measurements were done once or twice between 08:00 and 12:00 at time intervals of $2 \mathrm{~h}$ during which we consecutively used all transport modes once. Background levels of $\mathrm{PM}_{10}$ and $\mathrm{PM}_{2.5}$ during the respective time periods were obtained using local pollution data provided by the city government (Municipal Department 22). Mean ambient mass concentrations shown in Table 1 were calculated using data from three stationary measuring devices at the Viennese General Hospital (N48 ${ }^{\circ} 13^{\prime} 10.3^{\prime \prime} \mathrm{E} 16^{\circ} 20^{\prime} 44.0^{\prime \prime}$ ), Stadlau ( $\left.\mathrm{N}^{\circ} 8^{\circ} 13^{\prime} 34.9^{\prime \prime} \mathrm{E} 16^{\circ} 27^{\prime} 30.0^{\prime \prime}\right)$ and Taborstraße (N48 $\left.13^{\prime} 0.3^{\prime \prime} \mathrm{E} 16^{\circ} 22^{\prime} 51.3^{\prime \prime}\right)$.

\section{Characteristics of transport vehicles}

The chosen section of the subway line runs underground for approximately two thirds of the route. Trains (Bombardier ${ }^{\circledR}$ T, T1) were partially air-conditioned and mostly ventilated via open windows. Buses (MAN Lion's city ${ }^{\circledR}$, Mercedes-Benz Citaro ${ }^{\circledR}$ 2) were air-conditioned and powered by diesel engines. Trams (types A, B, E1, E2) were not air-conditioned and ventilated via open windows. Test cars (Audi A3 ${ }^{\circledR}$ 1997, Mazda $5^{\circledR} 2006$ and Ford B-Max ${ }^{\circledR}$ 2015), were all gasoline-powered and air-conditioned with air flow manually set to low. Windows were closed and the cabin was ventilated with ambient air. The bike route runs mostly directly next to traffic. Measuring devices were placed on passenger seats $2 \mathrm{~m}$ away from entry doors in public transport vehicles, on the left rear passenger seat in cars and strapped to the test person's back with air inlets at breathing level on the bicycle.

\section{Measuring devices}

We measured $\mathrm{PM}_{10}, \mathrm{PM}_{2.5}$ and $\mathrm{PM}_{1}$ mass concentrations of fine particles in 6-s intervals using the portable optical particle counter Grimm Aerosol
Spectrometer ${ }^{\circledR}$, Model 1.108 (GRIMM Aerosol Technik Ainring $\mathrm{GmbH} \&$ Co. KG, Ainring, Germany), the performance of which has been evaluated before [16] and which detects particles with an aerodynamic diameter over $300 \mathrm{~nm}$. Number concentrations of ultrafine particles between 300 and $10 \mathrm{~nm}$ were obtained in 1-s intervals using the miniDISC ${ }^{\circledR}$ diffusion size classifier (Dr. Martin Fierz, Fachhochschule Nordwestschweiz, Windisch, Switzerland) and LDSA was estimated according to the International Commission on Radiological Protection (ICRP) [17].

\section{Statistics}

The FPM, UFP and LDSA data were summed up into one mean for each commute. We observed minimal differences in traffic and background pollution levels during the 2-h measuring intervals and treated the consecutively obtained means as simultaneously measured data points. After testing all samples for Gaussian distribution with KolmogorowSmirnow tests we used Friedman's analysis of variance by rank for dependent samples to test for significant differences between mean FPM and UFP mass/ number concentrations and LDSA. When significant differences were indicated, post hoc analyses were done using Dunn-Bonferroni tests.

\section{Adjusting for different velocities}

We compared FPM, UFP and LDSA data with and without adjusting for different speeds, which was done by dividing the obtained data by the calculated mean speeds of the respective traffic modes, i. e. $7.6 \mathrm{~m} / \mathrm{s}$ for subway, $4.6 \mathrm{~m} / \mathrm{s}$ for bus, $5.8 \mathrm{~m} / \mathrm{s}$ for tram, $6.5 \mathrm{~m} / \mathrm{s}$ for car and $4.5 \mathrm{~m} / \mathrm{s}$ for bicycle.

\section{Results}

We obtained the set of data shown in Table 1. We were not able to do measurements in every single transport vehicle every time. Using the available data we did three seperate comparisons. Comparison one was done between subway, bus and tram. We used all 11 measurements to explore for differences in UFP exposure and all but measurement 2 to explore for differences in FPM exposure. In the second comparison the car was included. We used measurements 1, 3, 6 and 7 to explore for differences in UFP and FPM exposure. The third comparison was between subway, bus, tram and bicycle. For FPM comparisons we used measurements 8-11 and for UFP comparisons we additionally used measurement 2.

Table 2 shows obtained median mass concentrations of $\mathrm{PM}_{10}, \mathrm{PM}_{2.5}$ and $\mathrm{PM}_{1}$, as well as particle number concentrations of ultrafine particles and LDSA. 
Table 1 Background levels of PM10 (PM10-ba) and location of measurements of fine particulate matter (FPM) and ultrafine particulate matter (UFP)

\begin{tabular}{|c|c|c|c|c|}
\hline M & Date & $\mathrm{PM}_{10}$-ba $\left(\mu \mathrm{g} / \mathrm{m}^{3}\right)$ & FPM data & UFP data \\
\hline 1 & 27.10.2015 & 29.1 & $\mathrm{~s}, \mathrm{~b}, \mathrm{t}, \mathrm{c}$ & $\mathrm{s}, \mathrm{b}, \mathrm{t}, \mathrm{c}$ \\
\hline 2 & 17.11.2015 & 27.8 & - & $\mathrm{s}, \mathrm{b}, \mathrm{t}, \mathrm{bi}$ \\
\hline 3 & 23.02.2016 & 33.7 & $\mathrm{~s}, \mathrm{~b}, \mathrm{t}, \mathrm{c}$ & $\mathrm{s}, \mathrm{b}, \mathrm{t}, \mathrm{c}$ \\
\hline 4 & 25.02.2016 & 19.9 & $\mathrm{~s}, \mathrm{~b}, \mathrm{t}$ & $\mathrm{s}, \mathrm{b}, \mathrm{t}$ \\
\hline 5 & 25.02.2016 & 19.9 & $\mathrm{~s}, \mathrm{~b}, \mathrm{t}$ & $\mathrm{s}, \mathrm{b}, \mathrm{t}$ \\
\hline 6 & 01.03.2016 & 14.0 & $\mathrm{~s}, \mathrm{~b}, \mathrm{t}, \mathrm{c}$ & $\mathrm{s}, \mathrm{b}, \mathrm{t}, \mathrm{c}$ \\
\hline 7 & 01.03.2016 & 14.0 & $\mathrm{~s}, \mathrm{~b}, \mathrm{t}, \mathrm{c}$ & $\mathrm{s}, \mathrm{b}, \mathrm{t}, \mathrm{c}$ \\
\hline 8 & 02.06.2016 & 10.8 & $\mathrm{~s}, \mathrm{~b}, \mathrm{t}, \mathrm{bi}$ & $\mathrm{s}, \mathrm{b}, \mathrm{t}, \mathrm{bi}$ \\
\hline 9 & 02.06.2016 & 10.8 & $\mathrm{~s}, \mathrm{~b}, \mathrm{t}, \mathrm{bi}$ & $\mathrm{s}, \mathrm{b}, \mathrm{t}, \mathrm{bi}$ \\
\hline 10 & 06.06 .2016 & 19.5 & $\mathrm{~s}, \mathrm{~b}, \mathrm{t}, \mathrm{bi}$ & $\mathrm{s}, \mathrm{b}, \mathrm{t}, \mathrm{bi}$ \\
\hline 11 & 06.06 .2016 & 19.5 & $\mathrm{~s}, \mathrm{~b}, \mathrm{t}, \mathrm{bi}$ & $\mathrm{s}, \mathrm{b}, \mathrm{t}, \mathrm{bi}$ \\
\hline \multicolumn{5}{|c|}{$\begin{array}{l}\text { M Measurement, } s \text { subway, } b \text { bus, } t \text {. tram, } c \text { car, bi bicycle, } P M 10 \text {-ba back- } \\
\text { ground levels of } \mathrm{PM}_{10} \text {, FPM fine particulate matter, } \mathrm{PM}_{10}, \mathrm{PM}_{2,5} \text { and } \mathrm{PM}_{1} \\
\text { were measured in/on the respective traffic vehicles, UFP data ultrafine } \\
\text { particles and LDSA were measured in/on the respective traffic vehicles }\end{array}$} \\
\hline
\end{tabular}

\section{Subway vs. bus vs. tram}

We found significantly higher median $\mathrm{MC}\left(\mu \mathrm{g} / \mathrm{m}^{3}\right)$ of $\mathrm{PM}_{2.5}$ and $\mathrm{PM}_{1}$ in the subway compared to the bus (19.9 vs. $8.2, p<0.001$ and 12.7 vs. $5.8, p<0.001$, respectively). Fig. 2 shows that $\mathrm{PM}_{2.5}$ and $\mathrm{PM}_{1}$ mass concentrations were consistently lower in all 10 measurements.

The mean PNC of ultrafine particles $\left(\mathrm{pt} / \mathrm{cm}^{3}\right)$ was higher in the tram when compared to the subway as (11,783 vs. $7233, p=0.017$ ). Individual measurements are shown in Fig. 3.

No statistically significant differences were observed for $\mathrm{PM}_{10}$ mass concentrations and LDSA.

\section{Subway vs. bus vs. tram vs. car}

Mass concentrations of $\mathrm{PM}_{10}, \mathrm{PM}_{2.5}$ and $\mathrm{PM}_{1}\left(\mu \mathrm{g} / \mathrm{m}^{3}\right)$ in the subway were more than three times as high as in the car (72.7 vs. $19.2, p=0.016,21.9$ vs. 4.5 , $p=0.006$ and 11.4 vs. $3.0, p=0.006$, respectively). Fig. 4 shows that $\mathrm{PM}_{10}, \mathrm{PM}_{2.5}$ and $\mathrm{PM}_{1}$ levels were consistently lower in the car compared to the subway. No significant differences were observed for UFP and LDSA.

\section{Subway vs. bus vs. tram vs. bicycle}

Median LDSA $\left(\mu^{2} / \mathrm{cm}^{3}\right)$ on the bicycle was almost 9 times as high as in the subway (35.47 vs. $4.00, p=$ 0.042). Individual measurements are shown in Fig. 5. We did not find any significant differences in $\mathrm{PM}_{10}$, $\mathrm{PM}_{2.5}$ and $\mathrm{PM}_{1}$ and UFP exposure.

\section{Adjusting for different velocities}

Table 3 shows median mass concentrations, number concentrations, as well as LDSA adjusted for the respective velocities of the traffic mode. Adjusted PNC of ultrafine particles $\left(\mathrm{pt} / \mathrm{cm}^{3}\right)$ and LDSA $\left(\mu \mathrm{m}^{2} / \mathrm{cm}^{3}\right)$ were significantly different in the bus when compared to the subway (2673.4 vs. 951.8, $p<0.001$ and 1.1 vs. $0.47, p=0.004$, respectively). as well as in the tram compared to the subway (2031.6 vs. 951.8, $p=$ $0.017 / 0.86$ vs $0.47, p=0.32$, respectively).

Adjusted $\mathrm{PM}_{10}, \mathrm{PM}_{2.5}$ and $\mathrm{PM}_{1}$ mass concentrations $\left(\mu \mathrm{g} / \mathrm{m}^{3}\right)$ were significantly higher in the subway than in the bus (9.57 vs. $2.95, p=0.037,2.88$ vs. 0.69 , $p=0.037$ and 1.5 vs. $0.46, p=0.016$, respectively). Adjusted PNC of ultrafine particles $\left(\mathrm{pt} / \mathrm{cm}^{3}\right)$ as well as LDSA $\left(\mu \mathrm{m}^{2} / \mathrm{cm}^{3}\right)$ were significantly different in the bus when compared to the subway (2304 vs. 852.7, $p=0.004$ and 0.79 vs. $1.4, p=0.02$, respectively). The

Table 2 Median mass concentrations (PM), particle number concentrations (PNC) and lung deposited surface area (LDSA)

\begin{tabular}{|c|c|c|c|c|c|}
\hline & $\mathrm{PM}_{10}\left(\mu \mathrm{g} / \mathrm{m}^{3}\right)$ & $\mathrm{PM}_{2.5}\left(\mu \mathrm{g} / \mathrm{m}^{3}\right)$ & $P M_{1}\left(\mu g / m^{3}\right)$ & $\operatorname{UFP}\left(\mathrm{pt} / \mathrm{cm}^{3}\right)$ & $\operatorname{LDSA}\left(\mu \mathrm{m}^{2} / \mathrm{cm}^{3}\right)$ \\
\hline \multicolumn{6}{|c|}{ Comparison 1} \\
\hline Subway & 58.1 & 19.91 & 12.72 & 7233.33 & 3.56 \\
\hline Bus & 35.2 & 8.21 & 5.82 & 12296.0 & 5.05 \\
\hline Tram & 37.0 & 13.3 & 8.1 & 11783.23 & 5.01 \\
\hline \multicolumn{6}{|c|}{ Comparison 2} \\
\hline Subway & 72.74 & 21.95 & 11.46 & 6480.5 & 5.99 \\
\hline Bus & 27.8 & 6.2 & 3.8 & 10598.3 & 6.46 \\
\hline Tram & 51.1 & 14.8 & 6.9 & 10008.2 & 5.01 \\
\hline Car & 19.24 & 4.55 & $3.0_{6}$ & 8848.4 & 3.33 \\
\hline \multicolumn{6}{|c|}{ Comparison 3} \\
\hline Subway & 50.0 & 19.5 & 13.3 & 8608.9 & 4.007 \\
\hline Bus & 41.4 & 9.1 & 6.0 & 13129.9 & 6.32 \\
\hline Tram & 73.2 & 14.9 & 8.0 & 13311.5 & 7.49 \\
\hline Bicycle & 16.7 & 9.5 & 7.4 & 18199.6 & 35.477 \\
\hline
\end{tabular}




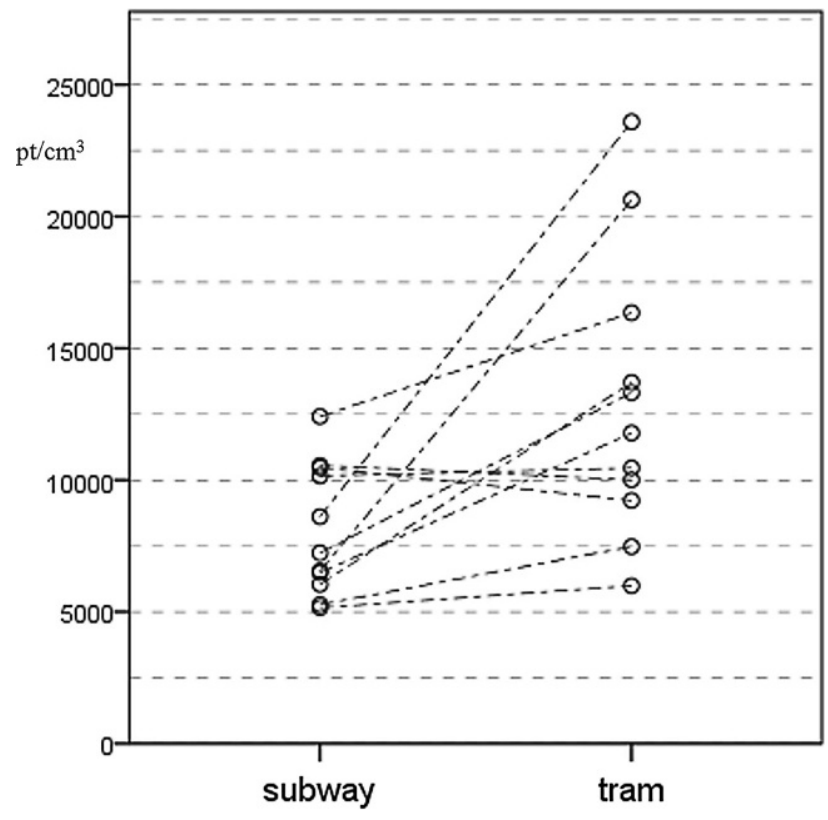

Fig. 3 Ultrafine particle number concentration data of subway and tram measurements, UFP exposure was higher in the tram during most measurements

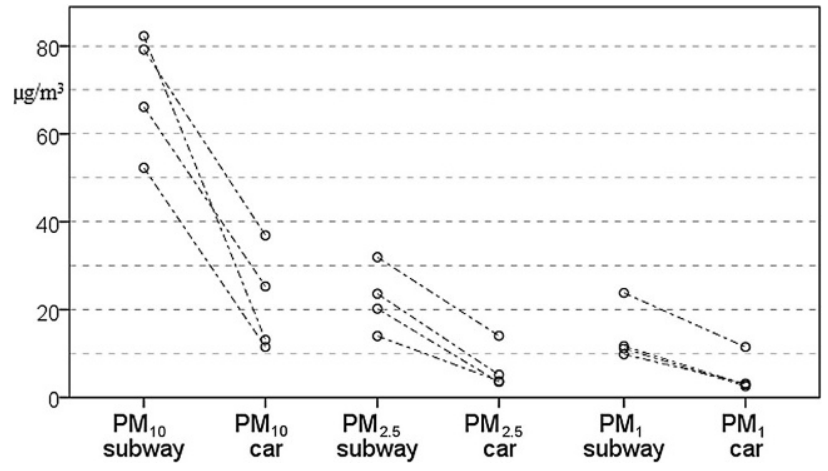

Fig. $4 \mathrm{PM}_{10}, \mathrm{PM}_{2.5}$ and $\mathrm{PM}_{1}$ data for subway and car

PNC of UFP and LDSA were significantly different on the bicycle when compared to the subway (4044.4 vs. $1132.8, p=0.009$ and 7.88 vs. $0.53, p=0.004$, respectively).

\section{Discussion}

We found higher levels of $\mathrm{PM}_{2.5}$ and $\mathrm{PM}_{1}$ in the subway when compared with the bus. A similar difference between bus and subway was found in Beijing in 2015 for mass concentrations of $\mathrm{PM}_{2.5}$ [11]. Different results were found in Hong Kong in 2001 where air-conditioned and non-air-conditioned bus passengers were exposed to higher levels of $\mathrm{PM}_{2.5}$ [14].

Despite their close distance to ambient traffic, bus passengers seem to be better protected from FPM than subway commuters in Vienna. This could be due to the lack of air filtration systems in older Viennese subway trains where ventilation often occurs via open windows. Large mass concentrations of FPM have been shown in other subway systems [18], especially on platforms and in train cabins [19] with openable windows [20]. Particles in subway systems contain elements associated with mechanical origin, such as brake or wheel abrasion [21] and could be created by the trains themselves. Air quality inside subway trains can be improved by implementation of air-conditioned train cabins [22] which are being used more and more in Vienna. By contrast, PNC of ultrafine particles were significantly lower in the subway when compared to the tram. Both traffic vehicles share many characteristics in Vienna, such as large, frequently opening doors and ventilation often occurring via windows. The tram line runs considerably closer to traffic which could explain the higher PNC levels of ultrafine particles. When comparing the car with the subway we found higher levels of $\mathrm{PM}_{10}, \mathrm{PM}_{2.5}$ and $\mathrm{PM}_{1}$ in the subway despite a larger distance to traffic. Similar results were found in Milan in 2016 [10], where mean $\mathrm{PM}_{10}, \mathrm{PM}_{2.5}$ and $\mathrm{PM}_{1}$ mass concentrations were lowest in the car and in Santiago de Chile in 2014 where $\mathrm{PM}_{2.5}$ was lowest in the car. The study conducted in Hong Kong 2001 showed different results and found higher exposure to $\mathrm{PM}_{10}$ in air-conditioned taxis than in the subway [14]. Low levels of FPM in cars have previously been shown in Vienna in a different study where ventilation occurred via one partly opened window [23].

Air filtration systems in cars seem to be somewhat more effective in reducing exposure to ambient FPM. It should be noted, however, that air flow was manually set to a low level. Penetration of fine particles into vehicle cabins occurs mainly via ventilation [24] and using higher fan speeds might have led to different results.

We found that median LDSA when travelling by bike was significantly larger than in the subway. This is most likely due to closer proximity of the bike route to road traffic and the absence of any isolation of the bike rider. We did not correct for different breathing patterns. Bike commuters usually take up more pollutants due to increased minute ventilation [25] but health benefits due to physical exercise may outweigh the risks of increased uptake [26, 27].

After adjusting for different velocities, no significant differences remained between FPM exposure of bus and subway passengers, due to the higher speed of the subway and the subsequent shorter time spent inside the vehicle cabin when travelling routes of the same length. Adjusted UFP number concentrations and LDSA were significantly lower in the subway when compared to the bus due to different speeds and, in the case of the tram, the vehicle characteristics already mentioned. Comparisons of subway and car with adjusted pollution data remained significant due to similar velocities of both transport modes. The LDSA and PNC of ultrafine particles were at significantly higher levels on the bike when compared to the subway. 
Table 3 Median mass concentrations, particle number concentrations and lung deposited surface area per distance

\begin{tabular}{|c|c|c|c|c|c|}
\hline & $\mathrm{PM}_{10}\left(\mu \mathrm{g} / \mathrm{m}^{3}\right)$ & $\mathrm{PM}_{2.5}\left(\mu \mathrm{g} / \mathrm{m}^{3}\right)$ & $\mathrm{PM}_{1}\left(\mu \mathrm{g} / \mathrm{m}^{3}\right)$ & $\operatorname{UFP}\left(\mathrm{pt} / \mathrm{cm}^{3}\right)$ & $\operatorname{LDSA}\left(\mu \mathrm{m}^{2} / \mathrm{cm}^{3}\right)$ \\
\hline \multicolumn{6}{|c|}{ Comparison 1} \\
\hline Subway & 7.64 & 2.62 & 1.67 & $951.81,2$ & $0.473,4$ \\
\hline Bus & 7.65 & 1.78 & 1.26 & $2673.4_{1}$ & $1.10_{3}$ \\
\hline Tram & 6.38 & 2.29 & 1.40 & 2031.62 & $0.86_{4}$ \\
\hline \multicolumn{6}{|c|}{ Comparison 2} \\
\hline Subway & 9.575 & 2.886 & 1.507 & 852.78 & $0.79 g$ \\
\hline Bus & 6.04 & 1.35 & 0.83 & $2304.0_{8}$ & $1.40 \mathrm{~g}$ \\
\hline Tram & 8.81 & 2.55 & 1.19 & 1725.6 & 0.86 \\
\hline Car & 2.955 & 0.696 & 0.467 & 1361.3 & 0.51 \\
\hline \multicolumn{6}{|c|}{ Comparison 3} \\
\hline Subway & 6.58 & 2.57 & 1.75 & 1132.810 & 0.5311 \\
\hline Bus & 9.00 & 1.98 & 1.30 & 2854.3 & 1.37 \\
\hline Tram & 12.62 & 2.57 & 1.38 & 2295.1 & 1.29 \\
\hline Bicycle & 3.71 & 2.11 & 1.64 & 4044.410 & 7.8811 \\
\hline
\end{tabular}

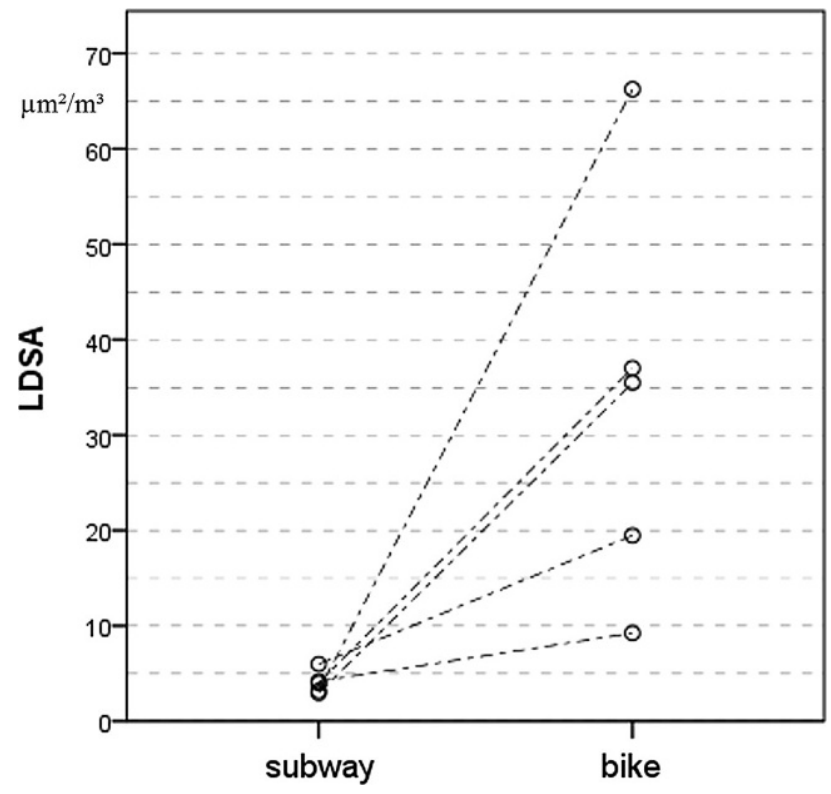

Fig. 5 Lung deposited surface area in subway and on bike

In general, exposure to ultrafine particles, which are mostly generated by combustion, seems to be higher near traffic (tram, bicycle), whereas coarser aerosol, either transported from street level or mechanically generated by trains, enters subway cabins.

\section{Reducing exposure}

The higher exposure to UFP closer to one of the main sources is not surprising. Reducing UFP concentrations can be done by reducing conventional traffic and moving public transport and bike lanes away from main traffic roads. Methods such as separating the bike lane from the road via a parking lane can be enough to significantly reduce exposure to ultra- fine particles [28]. The higher concentrations of FPM found in the subway are interesting. It seems as if the larger distance of underground trains to urban traffic does not necessarily protect the subway commuter from harmful pollutants. Particulate matter enters subway trains via active ventilation, open windows or open doors at the stations. The rising demand for comfortable temperatures in subway trains has already led to the implementation of air-conditioning, which, setting aside the additional energy costs, could be encouraged as it seems to be an effective way of lowering pollutants inside train cabins [22]. The same can most likely be said for trams but there are no studies confirming either hypothesis for Vienna yet. Presently, about $50 \%$ of the subway trains and $33 \%$ of the trams are air-conditioned, a situation encouraging new studies on differences in FPM and UFP exposure between those and the non-air-conditioned vehicles.

In addition, careful planning and setting of ventilation systems in new or existing subway stations should be encouraged. A recent study in Barcelona found that just changing ventilation fan directions has a significant effect on FPM concentrations on subway platforms [29]. Further studies in this area could have considerable effect, as optimizing ventilation protocols could be a cheap and quick method of lowering exposure to pollution. Air quality on platforms could also be improved by installation of platform screen doors [30].

\section{Conclusion}

For the respective areas of Vienna, we can issue a careful recommendation for taking the subway as a substitute for the tram. Despite lower exposure to pollution, we do not recommend taking the subway instead of the bicycle as the lack of exercise may offset the positive effects of lower exposure to pollution. From 
a public health point of view, we cannot recommend taking a car with combustion engine as a substitute for the subway, as the additional pollution created by the vehicle would have negative health effects on other commuters. Taking the bus instead of the subway can only be recommended if the target can be reached in the same time, on the same route length the subway is the preferable transport mode. We only measured FPM, UFP and LDSA data in a small area of Vienna to contribute to the growing pool of studies concerning individual commuter exposure to particulate matter. To draw more reliable conclusions for Vienna and other cities, further investigations need to include larger parts of the public transport and road systems and consider differences in vehicle ventilation.

Acknowledgements Open access funding provided by Medical University of Vienna. This work was performed as a diploma thesis at the Medical University of Vienna. Equipment was provided by the Commission of Climate \& Air Quality of the Austrian Academy of Science and calibrated by Prof. Dr. Hanns Moshammer.

Conflict of interest G. Strasser, S. Hiebaum, and M. Neuberger declare that they have no competing interests.

Open Access This article is distributed under the terms of the Creative Commons Attribution 4.0 International License (http://creativecommons.org/licenses/by/4.0/), which permits unrestricted use, distribution, and reproduction in any medium, provided you give appropriate credit to the original author(s) and the source, provide a link to the Creative Commons license, and indicate if changes were made.

\section{References}

1. Pope C III, Burnett RT, Thun MJ, et al. Lung cancer, cardiopulmonary mortality, and long-term exposure to fine particulate air pollution. JAMA. 2002;287:1132-41. https:// doi.org/10.1001/jama.287.9.1132.

2. Beelen R, Raaschou-Nielsen O, Stafoggia M, Andersen ZJ, Weinmayr G, Hoffmann B, et al. Effects of long-term exposure to air pollution on natural-cause mortality: an analysis of 22 European cohorts within the multicentre ESCAPE project. Lancet Lond Engl. 2014;383:785-95. https://doi.org/10.1016/S0140-6736(13)62158-3.

3. Katsouyanni K, Touloumi G, Spix C, Schwartz J, Balducci F, Medina S, et al. Short-term effects of ambient sulphur dioxide and particulate matter on mortality in 12 European cities: results from time series data from the APHEA project. Air pollution and health: a European approach. BMJ. 1997;314:1658-63.

4. Schwartz J, Dockery DW, Neas LM. Is daily mortality associated specifically with fine particles? J Air Waste Manag Assoc. 1996;46(10):927-39.

5. Stafoggia M, Schneider A, Cyrys J, Samoli E, Andersen ZJ, Bedada GB, et al. Association between short-term exposure to Ultrafineparticles and mortalityin eightEuropean Urban areas. Epidemiology. 2017;28:172-80. https://doi.org/10. 1097/EDE.0000000000000599.

6. Neuberger M, Rabczenko D, Moshammer H. Extended effects of air pollution on cardiopulmonary mortality in Vienna. Atmos Environ. 2007;41:8549-56. https://doi.org/ 10.1016/j.atmosenv.2007.07.013.
7. Neuberger M, Schimek MG, Horak F Jr., Moshammer $\mathrm{H}$, Kundi M, Frischer T, et al. Acute effects of particulate matter on respiratory diseases, symptoms and functions:: epidemiological results of the Austrian Project on Health Effects of Particulate Matter (AUPHEP). Atmos Environ. 2004;38:3971-81. https://doi.org/10.1016/j. atmosenv.2003.12.044.

8. Viana M, Kuhlbusch TAJ, Querol X, Alastuey A, Harrison RM, Hopke PK, et al. Source apportionment of particulate matter in europe: a review of methods and results. JAerosol Sci. 2008;39:827-49. https://doi.org/10.1016/j.jaerosci. 2008.05.007.

9. Laden F, Neas LM, Dockery DW, Schwartz J. Association of fine particulate matter from different sources with daily mortality in six U.S. cities. Environ Health Perspect. 2000;108:941-7.

10. Ozgen S, Ripamonti G, Malandrini A, Ragettli MS, Lonati G. Particle number and mass exposure concentrations by commuter transport modes in Milan, Italy. Environ. 2016;3:168-84. https://doi.org/10.3934/environsci.2016. 2.168.

11. Yan C, Zheng M, Yang Q, Zhang Q, Qiu X, Zhang Y, et al. Commuter exposure to particulate matter and particlebound PAHs in three transportation modes in Beijing, China. Environ Pollut. 2015;204:199-206. https://doi.org/ 10.1016/j.envpol.2015.05.001.

12. Suárez L, Mesías S, Iglesias V, Silva C, Cáceres DD, RuizRudolph P. Personal exposure to particulate matter in commuters using different transport modes (bus, bicycle, car and subway) in an assigned route in downtown Santiago, Chile. Environ Sci Process Impacts. 2014;16:1309-17. https://doi.org/10.1039/c3em00648d.

13. Moreno T, Reche C, Rivas I, Minguillón CM, Martins V, Vargas C, et al. Urban air quality comparison for bus, tram, subway and pedestrian commutes in Barcelona. Environ Res. 2015;142:495-510. https://doi.org/10.1016/j.envres. 2015.07.022.

14. Chan LY, Lau WL, Lee SC, Chan CY. Commuter exposure to particulate matter in public transportation modes in Hong Kong. Atmos Environ. 2002;36:3363-73. https://doi.org/ 10.1016/S1352-2310(02)00318-7.

15. Zuurbier M, HoekG, Oldenwening M, Lenters V, MeliefsteK, van den Hazel P, et al. Commuters' exposure to particulate matter air pollution is affected by mode of transport, fuel type, and route. Environ Health Perspect. 2010;118:783-9. https://doi.org/10.1289/ehp.0901622.

16. Burkart J, Steiner G, Reischl G, Moshammer H, Neuberger M, Hitzenberger R. Characterizing the performance of two optical particle counters (Grimm OPC1.108 and OPC1.109) under urban aerosol conditions. J Aerosol Sci. 2010;41:953-62. https://doi.org/10.1016/j.jaerosci.2010. 07.007 .

17. Asbach C, Fissan H, Stahlmecke B, Kuhlbusch TAJ, Pui DYH. Conceptual limitations and extensions of lung-deposited Nanoparticle Surface Area Monitor (NSAM). J Nanopart Res. 2009;11:101-9. https://doi.org/10.1007/s11051-0089479-8.

18. Johansson C, Johansson P-Å. Particulate matter in the underground of Stockholm. Atmos Environ. 2003;37:3-9. https://doi.org/10.1016/S1352-2310(02)00833-6.

19. Kim KY, Kim YS, Roh YM, Lee CM, Kim CN. Spatial distribution of particulate matter (PM10 and PM2.5) in Seoul metropolitan subway stations. J Hazard Mater. 2008;154:440-3. https://doi.org/10.1016/j.jhazmat.2007. 10.042.

20. Rivas I, Kumar P, Hagen-Zanker A, de Fatima Andrade M, Slovic AD, Pritchard JP, et al. Determinants of black 
carbon, particle mass and number concentrations in London transport microenvironments. Atmos Environ. 2017;161:247-62. https://doi.org/10.1016/j.atmosenv. 2017.05.004.

21. Querol X, Moreno T, Karanasiou A, Reche C, Alastuey A, Viana M, et al. Variability of levels and composition of PM10 and PM2.5 in the Barcelona metro system. Atmos Chem Phys. 2012;12:5055-76. https://doi.org/10.5194/acp-125055-2012.

22. Barmparesos N, Assimakopoulos VD, Assimakopoulos MN, Tsairidi E. Particulate matter levels and comfort conditions in the trains and platforms of the Athens underground metro. AIMS Environ Sci. 2016;3:199-219. https://doi.org/ 10.3934/environsci.2016.2.199.

23. Scheitel M, Stanic M, Neuberger M. PM10, PM2.5, PM1, number and surface of particles at the child's seat when smoking a cigarette in a car. AIMS Environ Sci. 2016;3:582-91. https://doi.org/10.3934/environsci.2016. 4.582 .

24. Geiss O, Barrero-Moreno J, Tirendi S, Kotzias D. Exposure to particulate matter in vehicle cabins of private cars. Aerosol Air Qual Res. 2010; https://doi.org/10.4209/aaqr.2010.07. 0054 .
25. Int Panis L, de Geus B, Vandenbulcke G, Willems H, Degraeuwe B, Bleux N, et al. Exposure to particulate matter in traffic: a comparison of cyclists and car passengers. Atmos Environ. 2010;44:2263-70.https://doi.org/10.1016/ j.atmosenv.2010.04.028.

26. de Hartog JJ, Boogaard H, Nijland H, Hoek G. Do the health benefits of cycling outweigh the risks? Environ Health Perspect. 2010;118:1109-16.

27. Andersen LB. Active commuting is beneficial for health. BMJ. 2017;357:j1740. https://doi.org/10.1136/bmj.j1740.

28. KendrickC, MooreA, HaireA, BigazziA, Figliozzi M, Monsere $\mathrm{C}$, et al. Impact of bicycle lane characteristics on exposure of bicyclists to traffic-related particulate matter. Transp Res Rec. 2011;2247:24-32. https://doi.org/10.3141/2247-04.

29. Moreno T, Reche C, Minguillón MC, Capdevila M, de Miguel E, Querol X. The effect of ventilation protocols on airborne particulate matter in subway systems. Sci Total Environ. 2017; https://doi.org/10.1016/j.scitotenv.2017.02.003.

30. Kim K-H, Ho DX, Jeon J-S, Kim J-C. A noticeable shift in particulate matter levels after platform screen door installation in a Korean subway station. Atmos Environ. 2012;49:219-23. https://doi.org/10.1016/j.atmosenv.2011. 11.058 . 